Vol. 3, n 1 | 1999

Varia

\title{
La « Cour du 19 août 1944 » : essai sur la mémoire policière
}

Jean-Marc Berlière

\section{(2) OpenEdition \\ Journals}

Édition électronique

URL : https://journals.openedition.org/chs/940

DOI : $10.4000 /$ chs.940

ISSN : 1663-4837

Éditeur

Librairie Droz

Édition imprimée

Date de publication : 1 janvier 1999

Pagination : 105-127

ISBN : 2-600-00356-8

ISSN : 1422-0857

\section{Référence électronique}

Jean-Marc Berlière, "La « Cour du 19 août 1944 » : essai sur la mémoire policière », Crime, Histoire \& Sociétés / Crime, History \& Societies [En ligne], Vol. 3, n¹ | 1999, mis en ligne le 06 avril 2009, consulté le 23 mars 2022. URL : http://journals.openedition.org/chs/940 ; DOI : https://doi.org/10.4000/chs. 940 


\title{
La «Cour du 19 août 1944»: essai sur la mémoire policière
}

\author{
Jean-Marc Berlière
}

Le rôle des administrations publiques et des fonctionnaires français sous l'Occupation fait aujourd'hui l'objet d'une véritable bataille autour de leur «mémoire». Dans ce contexte, il a semblé intéressant de voir comment et avec quelles difficultés et contradictions une institution comme la police gère sa propre mémoire des années noires. Après le temps des pages blanches et du silence, celui des légendes noires ou roses, le moment est-il venu pour une administration d'affronter ce que furent son rôle et l'attitude d'un groupe pris au piège de la légalité de Vichy comme de sa culture professionnelle et de ses intérêts corporatifs? Cela pose concrètement le problème des cultes et cérémonies mémoriels. Qui honorer, comment et pourquoi? Peut-on, doit-on continuer d'honorer la mémoire de policiers tombés en faisant leur devoir au service d'un régime devenu illégitime? Peut-on célébrer sans arrière-pensée l'attitude de policiers résistants qui ont certes sauvé l'honneur du corps, mais en donnant l'exemple même de l'indiscipline et de la transgression de tout ce qui fait l'essence et les valeurs sur lesquelles repose la police?

In the present context, in which "remembrance» battles are being waged over the role of the French public administrations and civil servants during the Occupation, it seemed worthwhile to look at how an institution such as the police copes with its own memories of those dark years, and the difficulties and contradictions it encounters. After years of blank pages and silence, followed by years of alternate dark and rosy legends, perhaps the time has come for the administration to face up to its own role, to its attitude as a group, entrapped in the formally legal nature of the Vichy régime, as well as in its own professional style and corporate interests. Concretely, this raises the problem of cults and memorial ceremonies. Who should be honored, and how and why? Can we, should we, continue to honor the memory of police officers who died in the line of duty in obedience to a régime that has lost its legitimacy since? Can we extol the stance taken by police officers who cooperated with the resistance, thus saving the corps' honor, without any mental reservation over the fact that in doing so they were overtly exemplifying indiscipline and transgression of the very essence of police values?

«L'intérêt bien compris d'une démocratie commande d'élever le niveau de la police et non de l'abaisser» (Célestin Hennion, Directeur de la Sûreté générale, projet de réforme 1911, AN F7 13 043).

\u déclenchement de l'insurrection, le 19 août, jusqu'à la victoire du 25 août, les fonctionnaires de la Préfecture de police ont été de tous les combats, au prix hélas! d'un lourd tribut. [...] Nous avons le devoir d'entretenir la 
flamme du souvenir de ces héros - policiers, sapeurs-pompiers, fonctionnaires administratifs de la Préfecture de police - qui, aux côtés de leurs camarades de la Résistance et de la $2^{\mathrm{e}}$ D.B., ont écrit cette page glorieuse de la capitale et de l'histoire de France. Dans leur lutte pour le rétablissement de la liberté et des droits de l'homme, 167 d'entre eux ont poussé le sens du devoir jusqu'à faire le sacrifice de leur vie »' C'est en ces termes que le Préfet de police présente les cérémonies qui se sont déroulées dans la «cour du 19 août 1944 » de la Préfecture de police, pour commémorer le cinquantenaire de l'insurrection qui marque le début des combats pour la libération de Paris.

Devant ces images diffusées dans les journaux télévisés, revenait en mémoire une autre commémoration: celle du 16 juillet 1992, Boulevard de Grenelle, devant l'emplacement du Vel d'hiv' où 50 ans auparavant avaient été enfermées 13152 personnes de «race juive »-dont 4115 enfants - raflées, parce qu'on leur en avait donné l'ordre, par ces fonctionnaires de la Préfecture de police dont on célèbrerait plus tard la lutte héroïque pour la liberté et les droits de l'homme.

Qui et que célébrait-on ce 19 août 1994 ?

La question mérite d'autant plus d'être posée qu'à la suite de cette commémoration de la libération de Paris, une exposition sur « la Préfecture de police des origines à nos jours » préparée dans le cadre d'une très officielle «mission du cinquantenaire ", s'installait entre la caserne de la Cité et le Palais de Justice. La Préfecture de police allait-elle profiter de cette occasion pour rendre l'ultime hommage de la vérité aux victimes de «la police de Vichy » qui avaient donné leur vie pour la liberté avec quelques années d'avance sur ses propres fonctionnaires? En fait, si l'attitude héroïque et le martyre des policiers parisiens y étaient à nouveau célébrés, pas un mot, pas un espace n'évoquait les rafles ou le rôle et la participation essentiels de la police parisienne à la répression menée pendant quatre ans contre des résistants et patriotes persécutés en même temps que ces droits de l'homme dont les policiers parisiens devaient devenir d'ardents défenseurs en août 1944.

L'administration venait de perdre une belle occasion de montrer, qu'après cinquante ans, le temps était peut-être venu de sortir des légendes complaisantes, des auto-glorifications et de la prétérition; que le temps était peut-être venu d'affronter une réalité plus nuancée, moins souriante et exaltante; que le temps était peut-être venu de considérer les Français en général et les policiers en particulier comme des citoyens responsables capables d'affronter la vérité ${ }^{2} .$.

Cet épisode met en lumière le problème de la mémoire policière et de ses rapports à l'histoire et au réel. Des mémoires devrions nous plutôt écrire, puisqu'à côté d'une mémoire officielle et institutionnelle souvent embarrassée, existent des mémoires individuelles, corporatives, syndicales, professionnelles, politiques et partisanes, toutes plus ou moins mythiques et reconstruites...

\section{Liaisons, juillet 1994, p. 3.}

2 Cette attitude contraste avec les efforts accomplis par la Gendarmerie Nationale pour assumer en partie ce passé. Le 26 juin 1992, en présence du ministre de la Défense, le directeur général de la Gendarmerie à l'occasion du baptême de la $96^{\text {eme }}$ promotion d'officiers, et avant un hommage appuyé aux gendarmes résistants, avait prononcé des paroles dont on chercherait en vain l'équivalent pour la Police nationale et a fortiori la Préfecture de police: «Il faut reconnaître [...] les souffrances que la Gendarmerie, comme d'autres services de l'État, a pu occasionner, volontairement parfois, involontairement le plus souvent, à toutes les victimes innocentes, combattants de l'ombre, déportés pour des motifs politiques ou raciaux, requis pour le S.T.O. [service du travail obligatoire en Allemagne auquel furent astreints les jeunes Français à partir de février 1943]» (cité par Cazals, 1994, p. 12). 
Un régime, une société, un État, un pouvoir, une nation ont la police qu'ils méritent ${ }^{3}$. Que penser d'un silence et d'une légende qui ne trompent personne, mais suscitent dans l'opinion publique les soupçons et les fantasmes les plus noirs, les analyses les plus folles?

Comment fonder une «police républicaine», comment gloser sur la déontologie policière en occultant ou en falsifiant le passé et le rôle réels de l'institution? Comment former des «policiers citoyens » en leur célant les dérapages passés de l'institution et les dérives de ses pratiques ? La négation ou la méconnaissance des réalités constituent-elles la meilleure des préparations à des responsabilités délicates qui peuvent parfois être dramatiques dans leurs conséquences? Comment espérer d'une police qu'elle puisse affronter en connaissance de cause ces problèmes fondamentaux que l'on trouve dans toute son histoire et qui ont pour origine: irresponsabilité, instrumentalisation, culture d'obéissance... sans lui permettre l'accès à une connaissance objective de son passé ? Comment s'étonner de l'obéissance passive dont ont fait preuve, de 1940 à 1944, la plupart des policiers aux ordres de l'État français, comment blâmer les comportements ouvertement racistes et xénophobes de certains si, aujourd' hui comme hier, on ne leur donne aucun moyen de mettre en perspective les responsabilités et les exigences morales d'une corporation que l'on méprise au point de lui déguiser sa propre histoire?

Certes, les «non-lieux de mémoire ${ }^{4}$ ont longtemps prévalu pour la période de l'Occupation. L'histoire de leur police s'inscrit dans les rapports difficiles et malsains des Français à ce «passé qui ne passe pas ». Elle relève de ce deuil impossible pour cause d'histoire falsifiée, d'histoire douloureuse à force d'être en si totale contradiction avec l'exigence qu'impliquent les responsabilités morales du «pays des droits de l'homme et de la liberté». Elle constitue un défi et une gageure tant elle a été manipulée. Or il n'est pas sain, il peut même être dangereux qu'une administration oublie ses errances passées. Des drames comme ceux des 16-17 juillet 1942 ou du 17 octobre $1961^{5}$ - ces deux soleils noirs qui projettent un jour lugubre sur l'histoire de la Préfecture de police - nécessitent d'être connus et lucidement analysés. «Il ne faut pas craindre de se souvenir de ce que des policiers français ont été amenés à faire en collaborant avec l'occupant. Il faut cultiver la honte de ces années noires pour que, jamais, cela ne se reproduise [...] J'aimerais [...] qu'on regarde en face la collaboration, les rafles, les tortures, l'antisémitisme, qu'on revienne sur les causes, qu'on explique aux futurs flics comment cette boucherie a été possible», écrivait il y a quelques années un responsable syndical ${ }^{6}$ de la police.

Nous aimerions ici non pas tant partir à la recherche d'une mémoire ou d'une vérité perdues? qu'éclairer, à travers l'exemple de la période de l'Occupation, les

3 Cf. sur ce sujet, les réflexions de Bertaux, un ancien directeur de la Police nationale (1963), et celles de Lantier, pseudonyme d'un policier devenu haut fonctionnaire de la Police nationale(1971).

4 Sur ce problème de mémoire voir par exemple les articles ou ouvrages cités de Chanteau (1995), Frank (1993), IHTP (1986), Kantin et Manceron (1991), Lindenberg (1994), Namer (1983), Rousso (1990), Thibaud (1991).

5 Répression meurtrière par la police parisienne d'une manifestation organisée par la fédération de France du F.L.N. (Front de Libération Nationale algérien). Un des épisodes controversés de cette répression se serait justement déroulé dans la «cour du 19 août» de la caserne de la Cité (J.L. Einaudi, 1991 et M. Papon in le Figaro du lundi 4 mai et du mardi 5 mai 1998).

- Deleplace (1987, p. 64).

7 Pour en savoir plus sur l'histoire des années noires et celle de la police, on pourra se reporter aux articles ou ouvrages cités et notamment à la tentative de mise au point que nous avons tenté de réaliser dans Berlière (1996b). 
rapports difficiles et contradictoires d'une institution à son histoire: en souligner les blancs et les silences; évoquer quelques-uns des mécanismes des récits légendaires - noirs ou roses - qui en tiennent souvent lieu; analyser les contorsions de la mémoire officielle entre commémoration des victimes d'un devoir professionnel contestable et exaltation d'une résistance dont la vertu essentielle résida dans un réflexe de désobéissance qu'on peut assimiler à la négation de l'essence même de l'institution.

\section{1. - PAGES BLANCHES POUR ANNÉES NOIRES}

L'histoire de la police contemporaine ${ }^{8}$ reste, en France, un chapitre à écrire au sein d'une période qui a elle-même longtemps constitué un « trou noir » historiographique: une singularité sur les causes et les conséquences de laquelle il convient de s'interroger rapidement.

Si la police a longtemps fait figure d'objet perdu des sciences sociales, les responsabilités doivent en être équitablement partagées entre l'institution elle-même et la communauté scientifique.

La première cause de ce déficit tient en effet à l'attitude d'une institution qui ne craint rien plus que la lumière et dont le sociologue canadien Jean-Paul Brodeur rappelle à juste titre qu'elle «s'est longtemps opposée au projet de connaître ${ }^{9}$. Les raisons de cette répugnance sont multiples.

Elles tiennent notamment à la croyance que sa puissance vient en partie des fantasmes, des mythes et des légendes qui l'entourent.

Elle tient ensuite à des méthodes et des actions qui se situent souvent en marge de la loi, ce qu'une institution chargée de veiller à son application ne souhaite pas voir étaler au grand jour.

Enfin, cette frilosité s'explique par une réelle incompréhension de l'intérêt que l'institution policière trouverait à la connaissance lucide et démythifiée de son passé ${ }^{10}$.

La conséquence pratique d'une telle méfiance est bien connue: elle se traduit notamment par la destruction d'archives sensibles avant versement ou le verrouillage de leur accès: une attitude qui donne quelque consistance - généralement la seule - aux campagnes des défenseurs du «devoir de mémoire» et aux citoyens militant pour la «libération» des archives ${ }^{11}$. Elle permet également aux historiens de se retrancher derrière un prétexte commode pour justifier leur ignorance ou leur désintérêt.

En réalité, même si cette difficulté est réelle, elle constitue plus un prétexte qu'un handicap rédhibitoire et il convient de s'interroger plus à fond sur les respon-

- Si cet essai ne concerne pas la gendarmerie, il va de soi que cela ne signifie en aucun cas que cette dernière aurait été épargnée par les syndromes décrits.

9 Brodeur (1984).

10 Ce déficit de connaissances se double d'un déficit politique et déontologique : il est hélas banal de rencontrer un commissaire de police parisien ignorant que les rafles qui ont eu lieu dans son quartier cinquante ans auparavant ont été le fait de ses aînés et non des Allemands (exemple rapporté par $\mathbf{M}$. Rajsfus, 1992: «la police a oublié»).

11 Sur les problèmes plus complexes qu'il n'y paraît liant citoyenneté et liberté d'accès aux archives, on lira les propos introductifs de J.N. Jeanneney à la table ronde consacré à ce sujet par l'Association des Archivistes français (1998, p. 165). 
sabilités de la communauté historienne dans un silence qui contraste fort avec la situation des pays anglo-saxons ou de l'Allemagne par exemple.

La première difficulté tient à l'objet même: la police, comme l'écrit le sociologue Dominique Monjardet, est un objet «sale» dont l'image rejaillit toujours plus ou moins négativement sur celui qui l'étudie ${ }^{12}$. Au soupçon d'être poussé par des motivations peu nobles se joint celui de l'instrumentalisation par une institution dont la manipulation est une des spécialités, voire celui de complaisance ou de naiveté. Ce sont là quelques-unes des raisons qui expliquent que si l'historien utilise volontiers le travail du policier, ce dernier soit resté transparent à ses yeux.

La deuxième série de questions concerne la «fermeture» des archives.

Notons d'abord qu'il s'agit en partie d'un mythe ou d'un prétexte. Il existe en effet pratiquement toujours un moyen de trouver ailleurs ou autrement ce que l'on cherche ${ }^{13}$.

Mais le vrai problème est celui de leur usage: des archives, mais pour quoi faire et pour y chercher quoi?

N'acceptant pas l'idée que le délai légal de consultation ${ }^{14}$ "protègerait » des gens qu'il assimile à des criminels au même titre que les chefs de la Gestapo, l'auteur d'un livre récent sur la «police de Vichy», s'indigne de ne pas avoir obtenu de dérogation pour consulter une liste nominative de policiers et de gendarmes ayant bénéficié d'une gratification spéciale pour leur travail de gardiens aux camps de Pithiviers et Beaune-la-Rolande ${ }^{15}$. Or, quand il écrit: «Puisque les Archives Nationales sont tellement discrètes lorsqu'il s'agit de communiquer des documents comportant des noms de policiers français au service de la Gestapo, il ne faut jamais hésiter à enfreindre cet interdit» ${ }^{16}$, il dévoile un but - dénoncer des "coupables», jeter des noms en pâture à l'opinion publique - qui n'est pas, qui ne peut pas être, du ressort d'une histoire à laquelle il assigne une tâche qui n'est pas la sienne: celle de «rattraper $»^{17}$ des coupables que la justice aurait laissé échapper et que protège le «silence administratif».

Outre le fait que comme l'écrit un de ces historiens «officiels» qu'il dénonce: «L'écriture de l'histoire ne consiste pas, comme le croient certains obsédés de la mémoire, à dresser des listes noires de collaborateurs, mais à comprendre et expli-

12 Monjardet (1985).

13 L'accès aux rapports du préfet de police pendant l'Occupation n'étant pas possible, on les trouvait certes en traduction allemande - dans des archives consultables (la série AJ40 des archives nationales qui contiennent les archives du Militärbefehlshaber in Frankreich). On ne peut avoir accès par le ministère de l'Intérieur aux dossiers personnels des policiers jugés à la Libération? Les séries Z6 (cours de justice), Z5 (chambres de justice) et $Z A$ (sections spéciales) qui concernent les procès de la Libération et dépendent du ministère de la Justice bénéficient d'un régime plus libéral. On pourrait multiplier les exemples de stratégies de remplacement, de sources de substitution auxquelles les historiens ont régulièrement recours. Pour des illustrations de ce propos, cf. D. Peschanski $(1986,1996 \mathrm{a}$ et b).

14 Trente ans depuis la loi sur les archives de 1979, mais soixante ans pour ce qui touche à la «sûreté de l'État » et a la vie privée: c'est sous ce prétexte - pas toujours fondé pour ce qui concerne la «sûreté de l'État " - que les archives de police ne sont pas consultables - sauf dérogation - avant ce délai. On lira divers points de vue sur ce problème dans Association des archivistes français (1998).

Rajsfus (1995, p. 17 et 19).

16 Ibid., p. 60. C'est nous qui soulignons.

17 [l'ex-commissaire Schweblin] «et tant d'autres que l'histoire finira par rattraper après bien des années de silence administratif» (Ibid., p. 61 : c'est nous qui soulignons). 
quer. C'est un métier, c'est même une éthique ${ }^{18}$, nous retrouvons là un problème familier aux historiens : celui de la recomposition erronée du passé.

Car enfin l'épuration, toute imparfaite et incomplète qu'elle fut, a bel et bien eu lieu et a touché des dizaines de milliers de Français y compris les policiers ${ }^{19}$. Même si elle a rapidement provoqué l'écœurement par ses excès ou au contraire déçu par sa faiblesse, même si la justice - essentiellement faute de pouvoir condamner sur la base d'un délit qui n'existait pas en tant que tel antérieurement aux faits - a semblé d'une indulgence coupable, même si des responsabilités que nous savons aujourd'hui accablantes lui ont échappé, d'où vient-il que la mémoire collective l'occulte au point de mettre en doute sa réalité ? S'il n'est pas question de se retrancher derrière une quelconque autorité de la chose jugée, il faut réaffirmer ici que les finalités de l'histoire et de la justice diffèrent notablement ${ }^{20}$.

\section{2. - LE MONDE DES LÉGENDES}

L'histoire officielle de la police sous l'Occupation donne une vision délibérément glorieuse et noble du comportement et de l'attitude des policiers. La commémoration du cinquantenaire de la Libération, par les publications auxquelles elle a donné lieu, par les témoignages et les déclarations officielles qu'elle a suscités, permet d'en observer quelques ressorts.

Pour l'occasion, la Préfecture de police, du moins «la mission du cinquantenaire » qu'elle a mise en place, a édité deux publications.

Un numéro spécial - «Libération de Paris, $50^{\text {eme }}$ anniversaire» - de son magazine Liaisons, consacré à la «Commémoration du soulèvement de la Préfecture de police», présente 48 pages abondamment illustrées de documents rares ou inédits: photos, témoignages, récits, fac-similés, mémoires de policiers, extraits de l'enregistrement des communications téléphoniques reçues au standard de la Préfecture pendant le soulèvement, plans, chronologie des événements du 13 au 26 août. C'est dire l'intérêt d'une livraison placée délibérément sous le signe du souvenir, mais également de l'histoire avec la caution d'un avant-propos de René Rémond historien reconnu qui a récemment dirigé plusieurs commissions chargées d'élucider des questions délicates ${ }^{21}$.

Parallèlement, pour l'édification des enfants et la joie des adeptes du « $8^{\text {ème }}$ art», une bande dessinée fut distribuée aux visiteurs de l'exposition sur l'histoire de la Préfecture. La couverture en montre le général de Gaulle décorant le drapeau des gardiens de la paix, le 12 octobre 1944 , sur fond de troupes de la $2^{\text {eme }}$ Division Blindée, de Parisiens enthousiastes et de caserne de la Cité surmontée du drapeau tricolore. Le titre - La fourragère rouge - précise le propos: il s'agit d'un récit de la Libération de Paris à travers l'action héroïque des policiers parisiens qui leur a valu cette décoration prestigieuse et inhabituelle par le premier des Français libres.

18 Rousso (1995).

.19 Sur le problème de l'épuration en général, on lira Rousso (1992), Conan et Rousso (1994); et de la police en particulier Berlière (1996a).

20 Si la chose jugée clôt un dossier juridique elle ne ferme pas le dossier historique. À l'inverse, on a vu, a l'occasion de récents procès, mettre en délibéré ce que l'histoire avait tranché depuis longtemps.

21 Cf. notamment Rémond (1996). 
Passons sur les invraisemblances, anachronismes et manipulations grossières de cette bande dessinée en notant toutefois que destinée aux enfants, elle présente une conception qui tient davantage du marketing, de la communication et de la propagande que de l'histoire et intéressons-nous de plus près à Liaisons dont l'ambition et la caution d'un historien reconnu rendent le contenu plus ambigu. Son propos ressortit à un mécanisme bien rodé et intangible depuis l'automne 1944: occultation totale des faits les plus gênants comme les rafles qui mettent en cause des milliers de fonctionnaires agissant sur ordre; condamnation sans équivoque d'une minorité de policiers dévoyés seuls auteurs de tous les crimes; exaltation de la Résistance policière et surtout de l'héroïque soulèvement.

L'élision totale des épisodes gênants pourrait sembler naturelle puisque le propos est de célébrer la Libération, mais ne solliciter l'histoire que pour cet événement glorieux, revient à souligner le silence dont, par contraste, souffrent les faits que jamais l'institution n'aborde.

Certains des témoins cités transgressent cette loi du silence. Leur qualité officielle de résistants leur permet d'évoquer des aspects moins glorieux laissés systématiquement dans l'ombre par la mémoire officielle. Sous le titre «Ils se souviennent», les présidents respectifs de la Fédération des anciens combattants et résistants de la Préfecture de police (FACRPP) et de l'Union des anciens combattants de la Préfecture de police (UACPP) ${ }^{22}$, font allusion, et ils sont bien les seuls dans cette publication, aux "méchants». Constituant l'antithèse des héros qui se sont battus pour la liberté, les policiers félons présentent l'avantage de mettre en valeur les autres, c'est-à-dire la majorité.

Le président de l'UACPP concède donc que: «le rôle des fonctionnaires de la Préfecture de police, pendant cette période, a donné lieu à de nombreuses controverses. Il y eut bien sûr les Brigades spéciales totalement inféodées à l'ennemi, collaborant avec un enthousiasme de mauvais aloi à la chasse aux patriotes (p. 37)». Quant au président de la FACRPP, il rappelle (p. 36) qu'en dépit de tant d'héroïsme il «ne faut pas oublier néanmoins qu'une minorité de policiers comme ceux des Renseignements généraux et des Brigades spéciales participèrent aux arrestations de patriotes et de Juifs morts en déportation ou fusillés", et il ajoute qu'ils «ont eu à répondre de leurs crimes devant la commission d'épuration et la cour de justice», ce qui est parfaitement exact.

Il y a donc bien eu des traîtres et des collaborateurs dans la police. Ils sont clairement identifiés: il s'agissait de policiers des Renseignements généraux et en particulier des Brigades spéciales, qui ont d'ailleurs payé pour leurs crimes. La concession est d'importance, elle crédibilise le discours, garantit son objectivité puisqu'on reconnaît la participation - que l'institution oublie ou occulte encore systématiquement - de policiers français à la lutte contre les patriotes. Cette «émissarisation » a l'avantage de circonscrire les mauvais policiers à quelques dizaines et à un service - les Renseignements généraux - qui de toutes façons n'a jamais eu bonne réputation. La stigmatisation des uns blanchit ipso facto les autres.

C'est si pratique et si commode qu'on va jusqu'à charger ces Brigades spéciales d'arrestations de Juifs dont elles sont en réalité totalement innocentes. Car si les policiers des Brigades spéciales ont arrêté des résistants qui étaient Juifs, notam-

22 L'existence de deux associations différentes d'anciens combattants, dont l'une fut dirigé par des proches ou des adhérents du PCF, comme leurs appellations respectives sont révélatrices d'autres conflits de mémoire et de leurs enjeux. 
ment le groupe Manouchian ${ }^{23}$, c'est comme «terroristes» et communistes, pas en tant que Juifs. Les Brigades spéciales sont même de tous les services de la Préfecture de police ceux qui ont le moins arrêté de Juifs, et jamais en tant que tels, contrairement à tous les autres services ${ }^{24}$, ce dont aucun des auteurs ne dit mot.

Bien au contraire, le président de la FACRPP l'affirme: «La grande majorité des policiers obéissait à leur ( $\mathrm{sic}$ ) conscience et de ce fait pratiquait une résistance individuelle et n'appliquait pas les ordres de Vichy qui leur (sic) étaient donnés d'arrêter des résistants, des Juifs ou des S.T.O.». Et le président de l'UACPP «confirme »: «Dans le même temps, fort heureusement, juste après la défaite, de nombreux fonctionnaires de la Préfecture de police se regroupent au sein d'un mouvement de résistance». On notera une petite divergence: résistance individuelle ou adhésion à un mouvement? Peu importe, l'essentiel est ailleurs. Après avoir minoré les dérives et circonscrit les responsabilités aux seules Brigades spéciales (BS), on transforme la majorité des policiers en résistants refusant d'appliquer des ordres infâmes. On vient d'aborder le dernier volet du triptyque: l'exaltation des vertus des bons policiers. Après quoi, il ne reste plus qu'à chanter la saga de la Libération: l'héroïsme qu'y démontrèrent des policiers tous - ou presque - résistants.

Une présentation aussi merveilleuse $e^{25}$ du passé, ne peut prospérer que sur l'oubli, la désinformation d'un public qui ne découvre les faits qu'à travers le prisme de la presse, du cinéma ou de livres médiatisés ${ }^{26}$. Elle se nourrit aussi des mécanismes de reconstruction de la mémoire chez les témoins et les acteurs eux-mêmes.

Cette mythification et l'amnésie ont leur prix: le développement d'une autre légende, noire celle-là.

Devant ce renversement de la réalité, l'occultation de responsabilités parfois criminelles, toujours écrasantes, l'absence totale ne serait-ce que d'une interrogation sur le rôle joué par l'institution, un sentiment de frustration et d'indignation a germé, exacerbé par les ratés, les inconséquences et insuffisances de l'épuration judiciaire.

Insensibles aux sirènes chantant les vertus de la paix civile et les nécessités de la réconciliation nationale, beaucoup restent scandalisés, bouleversés, confondus par tant de bonne conscience et d'assurance encouragées par le révisionnisme qui caractérise les années 1970. Commençant par la grâce accordée par le Président Pompidou au milicien Paul Touvier et se terminant par l'interview dans l'Express de Darquier, l'ancien Commissaire aux questions juives vivant une retraite paisible en Espagne et exposant avec impudence les thèses négationnistes, elles éclairent les compromissions d'un après-guerre qui apparaît rétrospectivement d'une tolérance coupable.

Ces sentiments sont à l'origine, dans les années 1980, d'une réaction parfaitement compréhensible dont les procès de Klaus Barbie, Paul Touvier, les affaires Leguay, Papon, Bousquet ${ }^{27}$ constituent des paroxysmes. Les passions encore brû-

23 Cf. Courtois, Peschanski et Rayski (1989) et Berlière, Peschanski (1997).

24 Y compris ceux de la Police judiciaire dont on ne parle jamais et y compris les policiers résistants.

25 "Qui dit ou fait des choses invraisemblables» (Dictionnaire Robert de la langue française).

26 Qui sont l'occasion pour des journalistes de «découvrir» et d'écrire qui sur les camps d'internement français, qui sur les «vichysto-résistants», qui sur le «fichier juif », la rafle du Vel' d'hiv, l'aryanisation des biens juifs... Chaque «découverte» étant l'occasion de controverses et de débats médiatiques qui ne brillent pas toujours par la rigueur scientifique et la méticulosité des recherches.

27 Hauts fonctionnaires en poste sous Vichy et inculpés de crime contre l'humanite. 
lantes attestent du poids du refoulé et montrent combien la France, faute de l'avoir affronté avec lucidité, souffre d'un deuil inachevé.

Il était donc normal qu'à cette occasion, des témoins, des survivants ou des descendants de victimes rappellent avec force leur vérité, leur expérience et s'indignent de l'oubli comme du renversement des rôles. Ces témoignages forts et indispensables, ces recherches précieuses contribuent à éclairer la réalité et à peindre des faces cachées d'une vérité complexe et tragique. On y voit apparaître un monde policier bien différent de celui que présente l'histoire officielle.

Mais le problème vient de ce que certains de ces ouvrages se présentant comme des travaux scientifiques, n'en respectent pas les buts, en transgressent les méthodes, et tombent ainsi dans le travers qu'ils dénoncent à juste titre dans l'histoire officielle. À trop vouloir prouver et dénoncer, ils oublient que l'historien, s'il ne saurait rester impassible, doit s'efforcer à l'impartialité et que son rôle est de comprendre et d'expliquer, jamais de juger. Le livre récent de Maurice Rajsfus sur La Police de Vichy ${ }^{28}$ dont le sous-titre - Les forces de l'ordre françaises au service de la Gestapo - annonce à la fois le parti-pris et la confusion, témoigne clairement de ces travers ${ }^{29}$.

\section{3. - LA MÉCANIQUE LÉGENDAIRE}

Si on perçoit bien les ressorts de la légende noire encouragée par le silence et l'occultation officiels, la construction de la légende rose appelle davantage de réflexion.

On connaît la boutade de Claude Bourdet, responsable du NAP ${ }^{30}$ : «On m'a toujours dit qu'il n'y avait que $2 \%$ de policiers collaborateurs. Manque de chance, je suis toujours tombé sur eux». Elle montre combien les résistants étaient, eux, sans illusion sur l'attitude des policiers français.

Dans ces conditions, comment expliquer la naissance et la pérennité d'une légende qui ne pouvait guère abuser des témoins bien placés pour juger de l'attitude et du rôle réels de la majorité des policiers français?

Pour comprendre le comment et le pourquoi de cette mystification, il faut bien garder à l'esprit que la police est au centre de l'État et revenir, dans la situation de l'été 1944, aux enjeux qui occupent les coulisses de la Libération.

Au delà de la joie, de la liberté retrouvée, c'est l'avenir politique du pays qui est en jeu. Les deux grandes composantes de la Résistance - gaullistes et communistes - ont besoin de la police dans leur jeu. Pour des raisons différentes, les uns et les

28 Le Cherche-midi, 1995.

29 La police française était-elle au service de Vichy ou de la Gestapo? C'est parce qu'il a pu affirmer qu'il avait defendu l'autonomie française contre l'occupant que Bousquet - secrétaire général à la police du gouvernement Laval - fut acquitté. S'agit-il de la police ou des forces de l'ordre? Le livre mélange allègrement des choses fort différentes: police et gendarmerie, mais également milice, «gestapo française » et officines paralleles comme la Police aux questions juives, le Service de police anticommuniste... sans qu'il soit toujours facile de savoir de quoi et de qui on parle. Enfin, tout à son propos de montrer que les policiers français étaient animés d'un zèle meurtrier, l'auteur - sans doute inconscient du révisionnisme de son argumentation - en arrive à minorer les responsabilités du gouvernement de Vichy et des hauts fonctionnaires de la police pour mieux accabler les exécutants. Noyautage des administrations publiques: organisation de résistance de fonctionnaires. 
autres vont concourir à une falsification et c'est parce qu'elle a été cautionnée par de tels parrains que la légende a pu perdurer.

Dans les circonstances et les incertitudes de la Libération, la police incarne la permanence et la continuité de l'État, la démonstration face aux alliés anglosaxons $^{31}$ de la capacité du nouveau pouvoir à gouverner, elle constitue, dans un climat insurrectionnel, un enjeu qui n'échappe à personne. Pour de Gaulle, elle est une garantie du retour à l'ordre ${ }^{32}$, un attribut et un outil indispensables du pouvoir et il n'a donc qu'un souci: la conserver forte et organisée. Pour les communistes, au contraire, elle constitue un obstacle à une éventuelle prise du pouvoir, il leur faut donc soit l'affaiblir, soit l'investir. Ainsi courtisée et convoitée, la police va être l'objet d'une double opération aux origines du mécanisme légendaire.

Séduction et magnanimité sont les moyens privilégiés par le chef de la France libre. C'est à la police parisienne, qu'avant même d'aller à l'Hôtel de Ville où l'attend le Conseil national de la Résistance, le général de Gaulle rend, au soir du 25 août, sa première visite dans la capitale libérée, marquant ainsi sa volonté de relégitimer le plus rapidement possible des policiers qui, en donnant le signal des combats, ont su saisir «l'occasion d'accroître leur prestige et leur popularitét ${ }^{33} » . \AA$ A travers la police, ce sont bien l'ordre, le régime, l'administration, l'État qui sont en jeu ${ }^{34}$.

Le nouveau pouvoir ne veut pas que la police - notamment à Paris - soit paralysée par l'usage qu'en a fait Vichy, c'est pourquoi, exploitant sans délai le rôle qu'elle a joué dans l'insurrection, il entreprend de la relégitimer et de la dédouaner par l'exaltation de l'héroïsme des policiers dans le combat libérateur et l'occultation de leur rôle sous l'Occupation. Dès le 26 août, une affiche signée Charles Luizet - le préfet nommé par de Gaulle - donne le ton, on peut y lire que «la police de Paris, qui $s$ 'est fièrement battue, n'oubliera jamais le concours aussi efficace que valeureux que les FFI lui ont apporté du 19 au 25 août pour la défense de la préfecture de police ». La suite éclaire le sens de ce renversement des rôles et la conclusion rappelle les enjeux politiques à qui les aurait oubliés: «des liens indissolubles unissent désormais le peuple de Paris et la police de Paris [...] L'ordre républicain reconquis les armes à la main, doit régner dans Paris délivré de l'ennemi et de la dictature».

Une bataille de la mémoire vient bel et bien de commencer. Son enjeu justifie quelque liberté avec la vérité historique et un pieux mensonge accrédité par le moins suspect des Français.

L'occultation des besognes accomplies, la célébration, dès la fin du mois d'août, du rôle joué par les policiers pendant les combats pour la Libération constituent la première étape d'une réécriture de l'histoire. Le chef de la France libre en ouvre solennellement la première page, le 12 octobre 1944, avec cette citation de la police parisienne à l'ordre de la nation, portant attribution de la Légion d'hon-

31 Qui avaient envisagé pour la France la mise en place - comme en Italie - d'un AMGOT (Allied Military Government of Occupied Territories) ce qui traduisait leur scepticisme quant à l'aptitude de la France libre et de la Résistance à gouverner le pays libéré.

32 «Je ne voulais pas qu'à la faveur du bouleversement, la capitale ne devînt la proie de l'anarchie», de Gaulle (1954, p. 364).

33 Ibid., p. 373.

34 «Pour ce qui est de l'ordre public, il sera maintenu par la police et la gendarmerie, avec, en cas de besoin, le concours des garnisons. Les milices n'ont plus d'objet. Celles qui existent seront dissoutes " Ibid., p. 386. 
neur ${ }^{35}$ et de la Croix de guerre: «Bravant l'occupant dès le 15 août, déclenchant la lutte dès le 19 et la poursuivant jusqu'au 26, les courageux gardiens de la police parisienne ont donné à toute la nation un bel exemple de patriotisme et de solidarité qui fut l'un des premiers facteurs du succès des combats pour la libération de la capitale».

L'opération réhabilitation allait réussir au delà de toutes espérances. Il aurait fallu bien de la mauvaise foi pour refuser un brevet de bonne conduite républicaine et résistante à une institution dont le rôle et le courage exemplaires étaient salués par le premier des résistants.

Mais d'autres acteurs - les communistes et les policiers eux-mêmes - ont joué leur rôle dans la bataille de la mémoire.

Comme nous l'écrivions plus haut: la police est au cœur de l'État. N'ayant pas renoncé à son objectif de prise du pouvoir ${ }^{36}$, le Parti communiste se veut donc au cœur de la police. Pour ce faire, il a imaginé de l'investir, à défaut de réussir à la remplacer par les Milices patriotiques qu'il contrôlait. C'est l'épuration qui va lui en fournir le moyen et l'occasion ${ }^{37}$. Plus elle sera profonde et plus il affaiblira un des remparts de l'État tout en créant des places disponibles pour des résistants communistes ou sympathisants.

L'objectif est de taille surtout dans deux domaines: le maintien de l'ordre et le renseignement politique ${ }^{38}$. C'est l'entrisme par le biais des Milices patriotiques dans les Compagnies républicaines de sécurité (CRS) créées en décembre 1945 qui permet aux communistes d'investir cette nouvelle force civile de maintien de l'ordre issue en partie des Groupes Mobiles de réserve (GMR) crés par Vichy. Pour les Renseignements généraux, non seulement les communistes ont éliminé - par l'épuration - ou "retourné» - par les dossiers dont ils se sont emparés - un certain nombre de spécialistes des services politiques qui étaient les plus fins connaisseurs du PCF, de ses mécanismes et rouages internes, de ses hommes et de ses cadres, mais ils ont largement pénétré une citadelle de l'État qui leur était jusqu'alors fermée. Ce faisant, ils accèdent à des dossiers qui seront fort utiles - avec les archives sur lesquelles les Soviétiques vont mettre la main - pour tenir un certain nombre de personnalités ou de fonctionnaires compromis avec l'occupant ${ }^{39}$.

Cette tactique explique que, même s'ils sont bien placés pour savoir qu'il reste dans la police énormément de policiers non résistants - comme subsistent dans les

35 Une pratique rarissime qui n'a été appliquée qu'à quelques unités décimées pendant la guerre 14-18 et qui déroge dans ce cas précis à toutes les règles en usage, mais qui vaut aux gardiens de la paix parisiens l'honneur de porter cette fourragère rouge si mal ressentie par leurs victimes et qui provoqua la surprise quelque peu indignee des hommes des Forces françaises libres si on en croit le témoignage de Pierre Messmer au colloque de Bayeux sur le rétablissement de la légalité républicaine (Institut Ch. de Gaulle, 1996, p. 540-541).

37 C'est pourquoi les communistes vont jouer un rôle moteur dans l'épuration de la Préfecture de police: non seulement en poussant leurs militants à dénoncer sans relâche ni faiblesse, les policiers qui les ont arrêtés ou traqués, mais surtout en s'emparant des rouages essentiels de l'épuration : la Commission d'épuration qui prononce les sanctions, la section d'épuration chargée des enquêtes, presidées, l'une et l'autre, par des communistes.

38 On note la même tentative - par le biais du $2^{\text {eme }}$ bureau des FFI (Forces françaises de l'intérieur) en direction des services spéciaux et du contre-espionnage (Cf. Faligot, Kauffer (1989) et Faligot, Krop (1985).

39 En voir un exemple in Jean Rochet, 1985, p. 32-58. 
CRS d'anciens hommes des GMR qui ont combattu les maquis -, les communistes ont tout intérêt, depuis qu'ils l'ont pénétrée, à promouvoir l'image d'une police républicaine issue de la Résistance.

Jusqu'à l'automne 1947, ils seront donc les complices consentants et intéressés du stratagème, tout en dénonçant l'insuffisance d'une épuration que de Gaulle, pas dupe, souhaitait réduite au strict minimum. Avec la "guerre froide», après la rupture du tripartisme, les grèves de 1947, l'épuration des épurateurs, le désarmement puis la dissolution des CRS communistes ${ }^{40}$, ils dénonceront la pérennité d'une police «fasciste» au service du «capital ». Mais il était trop tard, la relégitimation avait bel et bien eu lieu.

Dans cet avatar, on ne saurait enfin négliger le rôle des policiers. Ils devinrent d'actifs propagandistes d'une histoire légendaire centrée sur le sacrifice collectif d'expiation et de rachat de la semaine héroïque qui faisait oublier le rôle ambigu des anciens et flattait la fierté professionnelle des nouveaux venus. Mais pour construire une "police propre, républicaine et française » comme le réclamait, dès le 28 août 1944, un tract de policiers résistants, suffisait-il d'exalter le rôle de la police parisienne dans la libération de la capitale et d'occuper le territoire de la mémoire avec ces plaques de marbre rappelant au passant l'héroïsme des policiers de la Préfecture tombés dans les combats ? ${ }^{41}$ L'épuration - spectaculaire - permettait-elle d'occulter le problème fondamental: celui d'une police prise au piège par une collaboration d'État qui fit perdre de vue à beaucoup de policiers la réalité de leur mission ?

"L'histoire des années noires n'est pas un conte de fées ou de sorcières relatant l'histoire d'une poignée de bons et de méchants. Elle est l'histoire d'une tragédie humaine, et pleinement humaine, dont il est difficile, encore aujourd'hui, de comprendre toutes les pages grises ${ }^{42}$ : telle apparaît effectivement l'histoire de la police sous l'Occupation.

\section{4. - LES PAGES GRISES DE LA RÉALTÉ}

La méconnaissance du passé de l'institution, de son fonctionnement, de ses divisions... fait généralement perdre de vue que la période de l'Occupation représenta aussi pour la société policière l'occasion de faire avancer des revendications anciennes tout en réglant de vieux comptes internes et quelques contentieux externes. On doit également garder à l'esprit que l'existence d'un gouvernement légal, les clauses de l'armistice ${ }^{43}$, la politique de collaboration mise en œuvre par Vichy pour se concilier les bonnes grâces de son vainqueur et une place dans le futur ordre européen, valurent à la France un statut unique parmi les pays vaincus. Elles expliquent notamment la situation inédite, inconfortable et ambiguë d'une police qui se trouva au centre d'un double enjeu. Symbole de sa légitimité et de ses prérogatives d'état souverain, outil au service d'une politique autonome et spécifique de répression et d'exclusion pour l'État français, elle allait en outre devenir rapidement

\footnotetext{
40 Agulhon, Barrat, 1971.

41 Sauber, Annales ESC, 1993.

42 Conan, Rousso (1994, p. 103).

43 Dont l'article 3 obligeait l'administration française à assurer l'application des ordonnances allemandes.
} 
une pièce maîtresse de sa volonté de collaboration. Quant à l'occupant, il vit plus simplement dans la police française une auxiliaire inespérée dont le rôle, dans certaines circonstances, pouvait s'avérer précieux voire irremplaçable.

Instrument essentiel au maintien d'un ordre liberticide, la police française majoritairement composée de policiers de la III ${ }^{\mathbb{e}}$ République a plutôt bien accepté ce rôle du moins jusqu'en 1943. Pourquoi ? ${ }^{44}$

Sans doute parce qu'elle fut sensible à l'état d'esprit et aux premières mesures d'un pouvoir qui flattait une sensibilité idéologico-professionnelle que la III ${ }^{\mathrm{e}} \mathrm{Répu-}$ blique finissante avait exaltée. Elle fut encore plus sensible à la réalisation de quelques-unes des réformes que demandaient sans relâche, depuis des décennies, ses organisations corporatives. Les mesures du printemps 1941 qui mirent en place une «Police nationale» étatisée, centralisée et unifiée, qui se préoccupèrent de la formation et de la professionnalisation d'un corps proclamé «d'élite" auquel on accordait de surcroît de substantiels avantages pécuniaires et corporatifs, comblèrent les attentes du monde policier.

Si le régime de Vichy se situe dans la continuité de la $\mathrm{III}^{\mathrm{e}}$ République, ce n'est pas seulement parce qu'il en a prolongé la lutte anticommuniste et xénophobe, et achevé l'œuvre d'étatisation, c'est également parce qu'il en a conservé, en dépit de leur sensibilité politique supposée, la plupart des personnels et la quasi totalité du cadre: ce qui permit à beaucoup de policiers d'imaginer qu'ils continuaient le même travail. Mais la continuité n'était qu'apparente. Ce qui était l'exception sous la République, était devenu la règle, et la police - dont la mission est de veiller à l'application de la loi et de poursuivre ceux qui la transgressent - fut amenée à traquer des gens non seulement pour ce qu'ils faisaient, mais pour ce qu'ils étaient ${ }^{45}$, rompant ainsi avec une déontologie péniblement édifiée par 70 ans de République.

La multiplication d'officines parapolicières ${ }^{46}$ put faire, un temps, croire le contraire. Il semblait que ces créations traduisaient la méfiance qu'inspirait la police officielle aux fanatiques des groupuscules fascisants et aux ultras de la collaboration; qu'elles étaient une conséquence de la mollesse, du manque d'entrain manifestés par les policiers dans la construction de «l'Europe nouvelle», qu'elles prouvaient ainsi la réalité et la persistance d'une éthique professionnelle « républicaine ». Après tout, on ne pouvait pas confier n'importe quelle besogne aux policiers de métier. En réalité, le réflexe corporatif l'emporta largement sur la déontologie et le patriotisme. Cette concurrence stimula le zèle d'une police atteinte par le «syndrome du pont de la rivière Kwaï» ravie de prouver ses compétences à l'autre «meilleure police du monde».

Au triple motif d'affirmer l'autonomie de l'État français, de défendre un monopole professionnel et de préserver la légalité formelle, elle allait, notamment sous le secrétariat général de René Bousquet dont ce fut un des objectifs essentiels et l'écra-

44 La sensibilité d'un nombre non négligeable de policiers aux mots d'ordre xénophobes et anticommunistes de la Révolution nationale pose un rél problème quand on sait que la police, notamment parisienne, dont Vichy se méfiait terriblement et qu'il renonça à réformer, était largement pénétrée avant-guerre par un syndicalisme très marqué par la franc-maçonnerie et le radicalisme.

45 Quid d'une police des crimes et des délits quand l'appartenance à une société philosophique ou à une religion deviennent des délits?

46 Groupes de protection (GP), Police aux questions juives (PQJ), Service des sociétés secrètes (SSS), Service de police anticommuniste (SPAC) et leurs divers avatars, sans parler des truands employés par la Gestapo: «carlingue», bande Bonny-Lafont de la rue Lauriston dite "gestapo française "... 
sante responsabilité, prendre à sa charge toutes les missions répressives liées à la législation de Vichy et aux exigences allemandes. Prise au piège de la légitimité du nouveau pouvoir et de ses intérêts corporatifs, mais aussi d'une culture professionnelle qui lui faisait partager des aversions communes avec ses nouveaux maîtres, la police française fut amenée à jouer au service de l'occupant un rôle répressif majeur inédit en Europe occupée ${ }^{47}$.

Ce n'est donc pas une «minorité» de policiers, ce ne sont pas les seules brebis galeuses des Brigades spéciales (BS) et des Renseignements généraux comme l'écrivaient les policiers résistants, mais bel et bien l'institution dans son ensemble - comme la gendarmerie -, tous les services - administratifs et actifs, la tenue et les «bourgeois " ${ }^{48}$, les Renseignements généraux et la Police judiciaire, la Préfecture de police et la Police nationale - qui ont joué leur rôle dans la pièce comme le montrent la lutte «antiterroriste » et plus encore les persécutions antisémites.

Pour rivaliser avec les services parallèles crés par Pierre Pucheu, le secrétaire d'État à l'Intérieur, René Bousquet, le Secrétaire général à la police nommé par Laval en avril 1942, va donner à la Police judiciaire de la Police nationale les structures et les missions d'une police politique. Le 9 juin 1942, une circulaire du Secrétariat général annonce la constitution au sein de chaque Service régional de police judiciaire d'une section «nettement dégagée des affaires judiciaires de droit commun [...] uniquement chargée de la répression des menées communistes et terroristes ainsi que des menées antinationales de toute nature». Ces «Sections régionales des affaires judiciaires à origine politique» (SRAJOP) ou «sections de droit spécial» créées dans chaque direction régionale furent transformées, le 21 novembre 1942, en Sections des affaires politiques (SAP). Chaque Service régional de Police de sûreté - nouveau nom depuis le 4 octobre 1942, de la Police judiciaire - comporte depuis cette date une SAP. En coopération ou poussées par la concurrence du Service de répression des menées antinationales (SRMAN) de Charles Detmar, elles vont faire des dégâts considérables ${ }^{49}$.

À la Préfecture de police, c'étaient essentiellement les Brigades spéciales (BS) des Renseignements généraux crées en mars 1940 pour lutter contre le Parti Communiste hors la loi, qui furent chargées de la répression anticommuniste. Mais tous les services participèrent à la lutte antiterroriste.

La Police municipale parisienne ${ }^{50}$ elle-même fut contaminée par cette dérive. Elle avait, dès l'automne 1939, dû créer en son sein des «brigades speciales». Formées de 5 à 6 gardiens de la paix en civil, leur mission consistait à rechercher la propagande subversive et les individus qui l'assuraient. Transformées en 1942 en «Brigades spéciales d'interpellation» (BSi), leur activité, qui n'avait jamais cessé,

47 «Si nous avons pu avoir en France, une police moins nombreuse [qu'en Belgique et en Hollande] c'est parce qu'il existait un gouvernement établi et une police officielle au lieu d'une police auxiliaire comme dans les autres pays " (Déposition de Knochen, sept. 1948, tirée du dossier d'instruction de Bousquet citée par P. Froment, 1994, p. 221). À l'automne 1941, le personnel policier allemand affecté à l'occupation de la France - qui comporte encore la zone libre - ne comptait que 2900 personnes, moins qu'aux Pays-Bas (chiffre cité par Paxton, 1993, note 25, p. 615).

48 Policiers en civils.

4 Les spécialistes leur attribuent 12549 arrestations de mai 1942 a mai 1943: 7237 en zone sud, 5212 en zone nord. Pendant la même période, la Préfecture de police, à l'aide de ses propres services spécialisés pouvait se targuer de 3500 arrestations de communistes (Azéma, Peschanski, 1993, p. 370). 
prit, comme celle des Brigades spéciales (BS) des Renseignements généraux, une grande ampleur à partir de l'entrée des communistes dans la Résistance et des débuts de la lutte armée qui suivit l'attaque allemande de l'URSS à l'été 1941.

Les structures mises en place depuis la fin de la $\mathrm{III}^{\mathrm{e}}$ République jouent dès lors un rôle capital que leurs concepteurs n'avaient sans doute pas prévu. La Brigade spéciale (BS) des Renseignements généraux fut doublée d'une autre - la «BS2 »en janvier $1942^{51}$. Comptant chacune une centaine d'hommes au zèle sans cesse stimulé par le cadre hiérarchique et par des primes conséquentes, usant des fichiers et renseignements de la première section des Renseignements généraux, procédant à des surveillances et à des filatures de plusieurs semaines voire plusieurs mois, elles allaient faire des ravages dans les rangs du $\mathrm{PCF}^{52}$. Pour autant, on ne saurait oublier ceux commis par les brigades spéciales d'intervention de la police municipale. Formées de gardiens de la paix opérant les uns en civil, les autres en uniforme, elles opéraient inopinément, de jour comme de nuit, sur la voie publique, dans le métro et les lieux publics et sont à l'origine d'arrestations aussi nombreuses et spectaculaires que celles de leurs homonymes des RG.

$\mathrm{La}$ «solution finale de la question juive» rend plus dramatiques encore les persécutions antisémites auxquelles les policiers français donnèrent la main. Sans entrer dans le détail d'une évolution compliquée, notons que les missions répressives liées aux lois antisémites françaises et aux ordonnances allemandes ont été l'enjeu d'une lutte complexe entre Vichy, les autorités allemandes, le Secrétariat général pour la police et le Commissariat général aux questions juives (CGQJ) ${ }^{\mathbf{5 3}}$. C'est à la demande de Xavier Vallat, le Commissaire général, qui souhaitait disposer d'une police antijuive, que Vichy créa, en octobre 1941, la Police aux questions juives ( $\mathrm{PQJ}$ ) dont les effectifs étaient encadrés par des spécialistes allemands et, selon qu'il s'agissait de Paris ou de la province, quelques policiers détachés de la Préfecture de police ou de la Police nationale.

Dès la création de la $P Q J$, le problème de ses rapports avec les services officiels de police s'était posé. Pour répondre aux inquiétudes d'une administration jalouse de ses prérogatives, qui voyait d'un mauvais oil cette concurrence, Rivalland, le premier Secrétaire général à la police, avait pris soin de préciser que, recrutés directement par le CGQJ, les hommes de la $P Q J$ ne dépendaient que de lui et que leur rôle se limitait à la recherche des infractions au «décret portant statut des Juifs » du 2 juin 1941 et à leur communication aux services de police.

Succédant à Rivalland, Bousquet n'eut de cesse qu'il eût supprimé toutes les officines parallèles créées par Pucheu, au nombre desquelles la PQJ. Il exigea et obtint de Laval que les opérations judiciaires, notamment les arrestations et les perquisitions, fussent désormais effectuées par les seuls fonctionnaires de police sous son autorité. Dans la circulaire annonçant aux préfets régionaux la suppression, début juillet 1942, de la PQJ, il précisait: «les opérations judiciaires et notamment les perquisitions nécessitées par l'application de la législation sur les Israélites, seront effectuées par les fonctionnaires de la Police nationale. [...] Vous voudrez

51 Après avoir été créée dans un premier temps au sein de la Direction de la Police judiciaire qui souhaitait disposer - elle aussi - d'une brigade spéciale et des avantages - en termes de promotions, de primes - que cela procurait.

52 Cf. à ce sujet, Courtois, Peschanski, Rayski (1989).

53 Cf. à ce propos, les trois tomes pionniers de Billig consacrés au CGQJ (1995, 1957, 1960), ainsi que les ouvrages et articles cités de Klarsfeld et Froment. 
bien [...] confier l'exécution des dites opérations au Service national de la Police judiciaire, Section des affaires politiques ».

Tout à son souci de ne pas laisser échapper une parcelle de la répression, Bousquet mettait ainsi au compte de la police française une partie essentielle de la gestion de la question juive: les arrestations. Dans ce domaine inhabituel, elle allait démontrer, en dépit des doutes du S.S. Dannecker et de Darquier, le successeur de Vallat au CGQJ, qu'elle était capable d'une efficacité d'autant plus grande que l'émulation entre les différentes directions de la Préfecture de police et de la Police nationale allait jouer à plein également dans ce domaine.

Dans son ressort territorial, la Préfecture de police avait, dès 1941, joué un rôle pionnier: le détachement de policiers de la $3^{\text {eme }}$ section des Renseignements généraux à la $\mathrm{PQJ}$ atteste d'un intérêt précoce pour la question juive. La création d'une sous-direction des « affaires juives » au sein de la direction de la Police générale participe du même empressement. Ce laboratoire de la modernité n'allait pas tarder à se distinguer en mettant au point, grâce à l'expérience acquise à la fin des années trente dans la gestion des étrangers, un fichier à entrées multiples, constitué à partir du recensement des Juifs de la région parisienne imposé par l'ordonnance allemande du

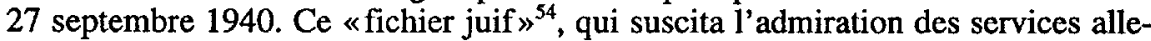
mands, servit à organiser toutes les rafles de mai 1941 à février 1944.

Mais pour supplanter la Section d'enquête et de contrôle (SEC) qui avait succédé à la $\mathrm{PQJ}$ dissoute, il fallait aller encore plus loin. Ce fut la mise en place d'un service répressif spécialisé. Rattaché à la Direction des étrangers puis, en 1943, à la Direction de la police judiciaire, ce Service des affaires juives fut confié à un commissaire principal aux Délégations judiciaires, délégué dans les fonctions de directeuradjoint de la Police judiciaire.

Ce rôle moteur de la Police judiciaire dans les persécutions ne représente pas la seule des dérives professionnelles qui affectent la pratique de tous les services. Dans le cadre de la concurrence séculaire qui les oppose entre elles, les autres directions de la Préfecture de police - ne voulant pas être en reste avec la Police judiciaire - ont tenu à mettre sur pied leur propre service antijuif. Ce fut le cas de la Direction des Renseignements généraux qui créa une section de voie publique (sic) - une révolution pour un service politique - au sein de la $3^{\text {eme }}$ section chargée «des Juifs et étrangers non terroristes». Cette brigade contrôlait les papiers des passants sur la voie publique à la recherche d'Israélites en contravention avec le statut du 2 juin 1941 ou les ordonnances allemandes et notamment le port de l'étoile, les heures légales de sortie ou la fréquentation des établissements publics. Une quinzaine d'inspecteurs opérant près des gares, dans le métro, les cafés, souvent accompagnés d'éléments du Parti Populaire Français voire d'Allemands du service «IV J » du SD, opérèrent plusieurs milliers d'arrestations. La Police municipale, qui jouait déjà un rôle essentiel dans les rafles, ne négligea pas pour autant les infractions à la législation antisémite et, pour non-respect des heures légales de sortie ou dissimulation d'étoile jaune, certains gardiens de la paix et certaines brigades spéciales d'intervention, notamment celles des $4^{\text {eme }}$ et $11^{\text {eme }}$ arrondissements, ont contribué à pourvoir le camp de Drancy en Juifs à déporter.

Prise au piège des habitudes de l'avant-guerre, de sa culture, de ses intérêts corporatifs, de son orgueil professionnel, la police le fut aussi de la volonté de collabo-

54 Voir à ce sujet, les mises au point apportées par la commission d'enquête présidée par René Rémond (1996). 
ration de Vichy dont les accords Oberg-Bousquet ${ }^{55}$ montrent la réalité: une police française amenée à remplir les tâches de l'occupant en échange d'une autonomie administrative et d'une reconnaissance de souveraineté que Vichy était prêt à payer à n'importe quel prix. Comme le remarque Robert Paxton, «Cette politique de présence administrative, sans cesse revendiquée, déboucha sur un activisme antijuif $~^{56}$. On connaît bien désormais la lettre adressée le 18 juin 1942 par Bousquet à Oberg ${ }^{57}$ : "Vous connaissez bien la police française. Elle a sans doute ses défauts, mais aussi ses qualités. Je suis persuadé que réorganisée sur des bases nouvelles et énergiquement dirigée, elle est susceptible de rendre les plus grands services. Déjà dans de nombreuses affaires, vous avez pu constater l'efficacité de son action. Je suis certain qu'elle peut faire davantage encore ".

Le test qui devait lui permettre de démontrer ses qualités fut la livraison des 40000 Juifs que Dannecker s'était imprudemment engagé au mois de juin à livrer à Eichmann et dont Bousquet obtint ${ }^{58}$, le 2 juillet, qu'il s'agisse de Juifs étrangers ou «apatrides» - c'est-à-dire déchus de la nationalité française par Vichy - et qu'ils soient arrêtés, par la seule police française, dans les deux zones ${ }^{59}$.

La Préfecture de police devait en fournir plus de la moitié, le solde devant provenir - à la discrétion des autorités françaises - de la zone non occupée. La rafle des 16 et 17 juillet à Paris 1942 fut donc - contrairement aux précédentes de mai, août et décembre 1941 - entièrement mise en œuvre par la seule Préfecture de police. On sait que si la Police municipale fournit la plus grande partie des effectifs d'une opération méticuleusement préparée par la Direction de la Police générale, Hennequin, le directeur de la Police municipale exigea la participation des effectifs des autres directions. Ce fut donc bien la totalité de la police parisienne, des milliers de policiers - gardiens de la paix et inspecteurs, de Paris et de banlieue - qui furent impliqués dans cette besogne que certains accomplirent avec zèle, d'autres avec répugnance. Quant aux Juifs étrangers et «apatrides» de la zone non occupée, ils furent déportés à partir du 6 août des camps de zone sud ${ }^{60}$ ou raflés, le 26 août, par les policiers de la Police nationale; des polices municipales et les gendarmes dans toutes les villes et les villages de la zone non occupée.

On le voit, on est loin de la légende d'une «majorité de policiers obéissant à leur conscience» et refusant d'appliquer les ordres de Vichy.

ss Mis en lumière et analysés par Klarsfeld $(1983,1985)$ qu'on pourra compléter par son article (1993, p. $545 s q)$.

56 Paxton (1993, p. 609).

57 AN-WIII-89, citée par Klarsfeld, (1983, p. 211). Pour le détail de ces négociations et la genèse des accords qui en résultèrent, on se reportera à cet ouvrage de référence, ainsi qu'à Froment (1994).

58 Il s'agit en l'occurrence d'une reculade et non d'un marchandage comme le montre Klarsfeld. C'est début mai, lors de sa rencontre avec Heydrich, que Bousquet prit l'initiative de proposer la livraison des Juifs apatrides (Cf. Paxton, 1993, p. 605sq). Pour les dissensions au sein des services allemands, on lira l'article cité de Klarsfeld (1993).

Accord entériné le lendemain en conseil des ministres et confirmé le 4 juillet par Laval à Oberg et Knochen.

60 Cf. Grynberg (1993). Vichy fut d'autant plus prompt à accepter cette livraison que l'État français vivait dans une peur constante de voir les nazis transformer la zone non occupée en «dépotoir des Juifs allemands " après les transferts opérés de façon autoritaire et unilatérale, en juillet, août et octobre 1940, de Juifs Alsaciens, de Juifs Allemands réfugiés à Bordeaux, puis des Juifs du pays de Bade et de Sarre-Palatinat (Cf. Marrus et Paxton, 1981, p. 24). 
Amenée par une législation méticuleuse à traquer des gens dont le seul crime était d'être légalement privés du droit à l'existence, la police atteignit clairement des limites déontologiques que peu de policiers eurent le courage civique et moral de ne pas franchir. Face à une «législation monstrueuse ${ }^{61}$, ils furent une infime minorité à avoir ce réflexe de désobéissance qu'éprouvèrent naturellement leurs collègues du service des étrangers de la police de $\mathrm{Nancy}^{62}$. Un réflexe qui s'opposait à toute une culture que les lois de septembre 1939 contre les communistes, celles de l'été 1940 contre les francs-maçons, les étrangers... avaient renforcée.

Sous couvert de devoir d'obéissance, c'est en réalité toute une morale et une culture professionnelles qui étaient foulées au pied. Une police judiciaire traquant des gens sur le seul «délit» de la religion de leurs grands-parents, des Renseignements généraux transformés en service répressif, une police municipale effectuant des missions proprement politiques montrent, avec l'emploi systématique de la violence, quelques-unes des dérives majeures d'une police pourtant héritée en grande partie de la III République. Loin d'avoir «évité le pire», comme le proclamèrent par la suite un certain nombre de cadres et de responsables, la prise en charge de ces missions par la police française a produit des résultats que ni la Milice, ni les Allemands n'auraient pu espérer. Croyant faire la «part du feu», les policiers français ont servi les intérêts de nazis qui n'en espéraient pas tant.

La vérité n'a rien de commun avec les légendes, elle oblige à dire que l'institution a exécuté fidèlement les ordres. En revanche, les policiers qui, dans leur écrasante majorité firent d'abord, au moins jusqu'en 1943, preuve de soumission et, pour certains, de zèle, évoluèrent au fur et à mesure que la tournure prise par la guerre rendit plus évident un retournement de situation. Une réelle passivité se développa peu à peu jusqu'à prendre les formes d'une désobéissance larvée.

En ce sens, les policiers ne furent pas différents du reste de la population française, mais leurs missions, leurs pouvoirs, leurs responsabilités rendirent cette attitude plus lourde de conséquences que pour n'importe quelle autre catégorie professionnelle. Ils arrêtèrent et raflèrent parce que c'étaient les ordres. On mesure ainsi le poids de la culture d'obéissance qui constitue l'essence même de la police et que tous les régimes se sont attachés à développer en son sein.

Ceci rappelé, on ne saurait sans illogisme à la fois fonder la formation et les qualités professionnelles de la police sur les notions d'obéissance aveugle aux ordres et au pouvoir établi, et s'étonner de leurs conséquences dans des circonstances extrêmes. Ni la formation reçue, ni la routine quotidienne, ni l'évaluation professionnelle n'avaient préparé ces policiers à l'idée même d'un devoir de désobéissance. C'est avec une douloureuse surprise que la plupart découvrirent à la Libération qu'une «apparence de légalité peut couvrir des actes illégitimes» ${ }^{63}$, que «le zèle est un acte de trahison», et que ces «bons Français» qui n'avaient pas hésité à

61 Notion que j'emprunte à Dominique Gros (1996) qui l'a développée et explicitée au colloque sur L'encadrement juridique de l'antisémitisme sous le régime de Vichy, Dijon, 19-20 décembre 1994.

Les policiers du service des étrangers de la police de Nancy, bien conscients des risques qu'ils prenaient, mirent tout en cuvre pour faire échouer les rafles en prévenant les Juifs menacés d'arrestation, en leur fournissant caches, filières et faux papiers... Ils parvinrent ainsi à sauver $80 \%$ de la communauté juive de l'agglomération (Cf. Muller, 1994).

63 Deleplace (1987, p. 62). Sur la lente intégration d'un «droit de désobéissance » par la déontologie policière, Cf. Muller (1994, p. $103 s q$ ). 
les seconder par leur vigilance et à soutenir leur zèle défaillant par des dénonciations, feignaient désormais de s'étonner et de s'indigner de leur obéissance et de leur soumission aux autorités. Ce changement des règles du jeu suscita l'incompréhension des intéressés et des anciens. «Si quand un chef vous donne un ordre, vous vous dites: est-ce que je dois l'exécuter, plus rien ne tient debout." ${ }^{64}$

Ces vérités peuvent-elles être prises en charge par l'institution?

Les récentes polémiques autour du nombre de victimes de la répression de la manifestation du 17 octobre 1961, les repentances publiques spectaculaires des évêques, d'un syndicat de policiers au moment du procès de Maurice Papon montrent que si les choses bougent c'est avec difficulté et toujours dans la douleur et la polémique: ce que l'on peut mesurer dans les embarras et contradictions de la mémoire officielle.

\section{5. - LES AMBIGUïTÉS DE LA MÉMOIRE OFFICIELLE}

«Ce fonctionnaire obéissait aux ordres de ses chefs. On ne peut pas dire qu'il était collaborateur, mais un peu trop discipliné». Cette conclusion d'un rapport, d'octobre 1945, du $3^{\mathrm{eme}}$ groupe de la section d'épuration de la Préfecture de police chargée d'enquêter sur le cas d'un inspecteur de la BS2 "victime du devoir», tué en 1942 par un déserteur allemand, montre bien quel fut - sous l'Occupation - le dilemme de policiers élevés dans le respect de la discipline. Elle pose deux questions essentielles: peut-on honorer les policiers morts par excès de discipline? Que doit privilégier une institution comme la police?

Le devoir professionnel? Certes. C'est d'ailleurs à ce titre que sont honorés les policiers victimes du devoir. Mais que faire quand ce devoir professionnel s'oppose à la morale, et pire encore à l'honneur?

Faut-il continuer à honorer des policiers qui ont fait leur devoir en obeissant jusqu'au sacrifice de leur conscience et de leur vie aux ordres donnés quand ces derniers les mettaient objectivement au service de l'occupant et les amenaient à commettre des actes illégitimes? Ou faut-il rendre hommage à un devoir d'une autre nature que 1'on respecte en désobéissant à des ordres qui nient les droits mêmes et la dignité des personnes, l'honneur qui conduit à enfreindre la sacro-sainte consigne quand elle déshonore ceux qui l'appliquent autant que ceux qui l'énoncent ou la transmettent ? Concrètement, la question pourrait se formuler ainsi: peut-on et fautil encore honorer des policiers tombés au service d'un camp et d'un ordre que l'histoire a condamnés, dans l'accomplissement de missions dont la finalité provoque gêne et malaise cinquante ans après? Mais, inversement, peut-on célébrer des policiers résistants que l'on assimila longtemps à des rebelles et qui constituent de dangereux exemples d'indiscipline $?^{65}$ Comment commémorer une grève et une insurrection qui si elles sauvent l'honneur du corps, le menacent dans son essence même? La police peut-elle sans risque et sans contradiction, célébrer une attitude qui représente la négation même de ce qu'elle doit être, de ce qui constitue sa raison d'être?

64 Réponse d'un gardien de la paix du $4^{e}$ arrondissement détaché à la Brigade spéciale d'intervention, au membre de la Commission d'épuration qui vient de lui dire qu'il aurait pu eviter d'appliquer une consigne.

65 Les policiers français ont gagné le droit syndical en 1948, la grève leur reste statutairement interdite. 
Si résister c'est d'abord transgresser les ordres, la discipline, la loi... comment exalter ceux qui ont désobéi en résistant?

Cette aporie apparaît clairement dans les silences ${ }^{66}$ gênés de l'institution et surtout dans les cultes mémoriels et cérémonies à bien des égards contradictoires dont elle est le cadre.

Pour mieux percevoir les ambiguïtés des célébrations officielles, retournons dans cette Cour du 19 août d'où nous sommes partis et cherchons-y, figées dans la pierre, les marques symboliques des hommages officiels.

La Préfecture de police honore quatre sortes de victimes: d'abord et comme toute administration qui se respecte, les policiers «morts pour la France», entendre sous l'uniforme français comme soldats pendant les guerres; les «victimes du devoir »; les policiers résistants, torturés, fusillés par les nazis ou morts en déportation; enfin les policiers «tombés dans les combats pour la libération de Paris». Il s'agit là - même si les familles ne saisissent pas toujours les nuances - de catégories bien distinctes qu'il convient d'honorer pour des raisons fort différentes.

Deux d'entre elles seulement ont leur monument dans la Cour du 19 août ${ }^{67}$. L'un dédié «À nos camarades morts pour la France», le second, aux «Policiers victimes du devoir».

Les policiers «tombés pour la libération de Paris» n'étant stricto sensu ni «morts pour la France», ni «pour le devoir», n'ont pas droit à un monument particulier $^{68}$. Pas plus d'ailleurs que les policiers résistants déportés ou fusillés ${ }^{69}$. Ces derniers ne sont pas morts pour la France mais pour l'idée qu'ils s'en faisaient. Ils ne sont pas morts pour le devoir, mais pour ce qu'ils estimaient être l'honneur: ce qui les a amenés à trahir leur devoir professionnel car en ces temps difficiles et confus, l'honneur, impliquait une rupture fondamentale avec la règle d'obéissance et le devoir professionnel.

Ainsi, alors que cette cour est baptisée «du 19 août» depuis le soulèvement de 1944 ses victimes n'y étaient rappelées par aucun monument jusqu'en août 1994.

C'est que si les policiers tués dans les combats d'août 1944 sont aussi morts par obéissance ${ }^{70}$ - et pour sauver l'honneur bien terni de la police parisienne-, ils le sont dans une action - une grève insurrectionnelle - et d'un côté inhabituel des barricades qui n'ont sans doute pas semblé dignes d'être rappelés dans la cour d'honneur de la Préfecture de police.

La mémoire officielle apparaît ainsi conjoncturelle et à " géométrie variable»: sur le temps long, on met plutôt en valeur les policiers dont la mort honore la profession et ses valeurs d'obéissance, de devoir, de discipline, d'abnégation, mais

o6 On notera que - toutes proportions gardées - le problème et la gêne sont de la même nature pour la Résistance allemande antinazie peu célébrée pendant longtemps en Allemagne parce qu'elle ne pouvait guère s'opposer à Hitler sans trahir la patrie.

67 On notera un problème du même ordre évoqué par Badinter (1997, p. 205sq) à propos des avocats morts pour la France de 1939 à 1945 et dont les noms figurent sur deux plaques différentes.

68 En revanche, leur sacrifice est rappelé à l'endroit où ils sont tombés, par des plaques de marbre portant leur nom entouré de symboles et palmes évoquant les décorations attribuées à la police parisienne par le chef du Gouvernement provisoire de la République en octobre 1944.

69 Par exemple Arsène Poncey, Edmond Dubent, arrêtés en 1943, torturés et morts en déportation, réels initiateurs d'une résistance dans la police parisienne.

70 Ce qui est attesté par le fait que les policiers qui n'ont pas obéi à l'ordre de grève insurrectionnelle ont été traduits devant la Commission d'épuration et souvent sanctionnés pour ce motif. 
dans certaines circonstances, il peut ne pas être inopportun de rendre un hommage, même tardif et discret, à ceux qui ont sauvé l'honneur du corps.

\section{Jean-Marc Berlière Université de Bourgogne 12, rue du Chapeau Rouge F-21000 Dijon} E-mail: berliere@alcyone.u-bourgogne.fr

\section{RÉFÉRENCES}

Association des archivistes français, Transparence et secret: l'accès aux archives contemporaines, La gazette des archives, 1998, $\mathrm{n}^{\circ} 177-178$.

Agulhon, M., Barrat, F., CRS à Marseille. La police au service du peuple 1944-1947, Paris, 1971.

Azema, J.P., Peschanski, D., Vichy état policier, in Azéma, J.P., Bédarida, F., (Dir.), La France des années noires, Paris, Seuil, 1993, t. 2, p. 357-375.

Badinter, R., Un antisémitisme ordinaire. Vichy et les avocats juifs (1940-1944), Paris, Fayard, 1997.

Belin, J., Trente ans de Sûreté Nationale, Paris, France soir éditions, 1950.

Berlière, J.M., Le passé recomposé: archives orales et histoire de la police, Cahiers de la sécurité intérieure, 1994, 17, p. 34-43.

Berlière, J.M., L'épuration de la police parisienne 1944-1945, XX siècle-Revue d'histoire, 1996a, 49, p. 63-81.

Berlière, J.M., Polices et policiers en France XIX ${ }^{e}-X X^{e}$ siècles, Bruxelles, Complexe, $1996 \mathrm{~b}$.

Berlière, J.M., Peschanski, D., Police et policiers parisiens face à la lutte armee: 1941-1944, in Berlière, J.M., Peschanski, D., (Dir.), Pouvoirs et polices au XX' siècle (Europe, USA, Japon), Bruxelles, Complexe, 1997, p.137-176.

Bertaux, P., On a la police qu'on mérite, La Nef, 1963, 14, p. 92-100.

Billig, J., Le commissariat aux questions juives (1941-1944), Paris, Éditions du Centre, 3 vol., 1955,1957 et 1960.

Brodeur, J.P., La police: mythes et réalités, Criminologie, 1984, XVII, 1, p. 9-41.

Buton, Ph., Les lendemains qui déchantent, le P.C.F. à la Libération, Paris, Presses de la FNSP, 1993.

Cazals, C., La gendarmerie sous l'Occupation, Paris, Éditions La Musse, 1994.

Chanteau, J.P., 17 octobre 1961: le deuil impossible, Territoires contemporains, 1995, 2, p. 95-113 (Dijon, Institut d'histoire contemporaine).

Conan, E., Rousso, H., Vichy un passé qui ne passe pas, Paris, Fayard, 1994.

Courtois, S., Peschanski, D., Rayski, A., Le sang de l'étranger. Les immigrés de la MOI dans la Résistance, Paris Fayard, 1989.

Deleplace, B., Une vie de flic, Paris, Gallimard (Folio), 1987.

Einaudi, J.L., La bataille de Paris (17 octobre 1961), Paris, Seuil, 1991.

Faligot, R., Krop, P., La piscine, les services secrets français 1944-1984, Paris, Seuil, 1985.

Faligot, R., Kauffer, R., Les résistants: de la guerre de l'ombre aux allées du pouvoir, Paris, Fayard, 1989.

Frank, R., La mémoire empoisonnée, in Azéma, J.P., Bédarida, F., (Dir.), La France des années noires, Paris, Seuil, 1993, t.2, p. 483-514. 
Froment, P., René Bousquet, Paris, Stock, 1994. Gaulle, Ch. de, Mémoires de guerre, L'unité, Paris, Livre de poche, 1954, t. 2.

Gros, D., (Dir.), Le droit antisémite de Vichy, Le genre humain, 30-31, Paris, Le Seuil, 1996. Grynberg, A., Les camps de la honte, Paris, La Découverte, 1991.

Grynberg, A., Les camps du sud de la France : de l'internement à la déportation, Annales ESC, $1993,48,3$, p. 557-566.

Institut Ch. de Gaulle, Le rétablissement de la légalité républicaine (colloque de Bayeux, 1994), Bruxelles, Complexe, 1996.

Institut d'Histoire du Temps Présent, La mémoire des Français. Quarante ans de commémorations de la Seconde Guerre mondiale, Paris, éditions du CNRS, 1986.

Kantin, G., Manceron, G., (Dir.), Les échos de la mémoire. Tabous et enseignement de la Seconde Guerre mondiale, Paris, Le Monde Éditions, 1991.

Klarsfeld, S., Vichy-Auschwitz. Le rôle de Vichy dans la solution finale de la question juive, 2 vol., Paris, Fayard, 1983 et 1987.

Klarsfeld, S., Les divergences dans l'appareil policier nazi et la réalisation de la solution finale en France, Annales ESC, 1993, 48, 3, p. 545-555.

Lantier, J., Le temps des policiers, trente ans d'abus, Paris, Fayard, 1971.

LIAISONS, magazine de la Préfecture de police, numéro spécial «commémoration du soulèvement de la Préfecture de police», juillet 1994.

Lindenberg, D., Guerre de mémoire en France, XXe Siècle-Revue d'Histoire, 1994, 42, p. 77. 95.

Marrus, M., Paxton, R., Vichy et les Juifs, Paris, Calmann-Lévy, 1981.

Monjardet, D., Police et sociologie: questions croisées, Déviance et Société, 1985, IX, 4, p. 297-311.

Muller, J.M., Désobéir à Vichy. La Résistance civile de fonctionnaires de police. Nancy, 19 juillet 1942, Nancy, Presses Universitaires de Nancy, 1994.

Namer, G., Batailles pour la mémoire. La commémoration en France de 1945 à nos jours, Paris, Papyrus, 1983.

Nicolaidis, D. (Dir), Oublier nos crimes. L'amnésie nationale, une spécificité française?, Autrement, 1994.

Paxton, R., La spécificité de la persécution des Juifs en France, Annales ESC, 1993, 48, 3 , p. 605-619.

«Présence du passé, lenteur de l'histoire. Vichy, l'Occupation, les Juifs», Annales E.S.C., 1993, 48, 3.

Peschanski, D., Pour une utilisation raisonnee des archives in Wolikow, S., (dir.), Une histoire en révolution. Du bon usage des archives, de Moscou et d'ailleurs, Dijon, EUD, 1996a, p.121-128.

Peschanski, D., Vichy, 1940-1944. Archives de guerre d'Angelo Tasca, Milan, Paris, Éditions du CNRS/ Feltrinelli, Annales de la Fondation Feltrinelli, 1986.

Peschanski, D., Bidussa, D., (Dir.), La France de Vichy, archives inédites d'Angelo Tasca, Milan, Feltrinelli, 1996 b.

«Que faire de Vichy ?», Esprit, 1992, 5.

Rajsfus, M., Jeudi noir. 50 ans après la rafle du 16 juillet 1942, Levallois-Perret, Manya, 1992.

Rajsfus, M., La police de Vichy, Les forces de l'ordre françaises au service de la Gestapo 1940/1944, Paris, Le Cherche-midi, 1995.

Rémond, R., Le «fichier juif». Rapport de la commission présidée par René Rémond au Premier Ministre, Paris, Plon, 1996. 
Rochet, J., 5 ans à la tête de la DST, Paris, Plon, 1985.

Rousso, H., Le syndrome de Vichy de 1944 à nos jours, Paris, Le seuil («Points Histoire»), 1990.

Rousso, H., L'épuration une histoire inachevée, $X X^{e}$ Siècle-Revue d'histoire, 1992, 33, p. 78105.

Rousso, H., Une justice impossible. L'épuration et la politique antijuive de Vichy, Annales ESC, 1993, 48, 3, p. 745-770.

Rousso, H., Archives: il n'y a pas de secret d'État! L'histoire, 1995, 186, 98.

Sauber, M., Traces fragiles. Les plaques commémoratives dans les rues de Paris, Annales ESC, 1993, 48, 3, p. 715-27.

Thibaud, P., La culpabilité française, Esprit, 1991, 1, p. 23-30. 